\title{
Can dietary interventions improve asthma control?
}

See linked article by Bime et al. on pg 398

\section{Raphaëlle Varraso ${ }^{1,2}$, *Carlos A Camargo Jr ${ }^{3}$}

1 Inserm, CESP Centre for Research in Epidemiology and Population Health, U1018, Respiratory and Environmental Epidemiology Team, Villejuif, France

2 Univ Paris Sud 11, UMRS 1018, Villejuif, France

3 Department of Emergency Medicine, Massachusetts General Hospital, Harvard Medical School, Boston, USA

*Correspondence: Dr Carlos A Camargo Jr, Massachusetts General Hospital, 326 Cambridge St, Suite 410, Boston, MA 02114, USA.

Tel: + 16177265276 Fax: + 16177244050

E-mail: ccamargo@partners.org

Over the past 40 years, asthma prevalence has doubled to approximately $8 \%$ of the US population. ${ }^{1}$ The causes of this dramatic change are unclear, but most experts attribute the increase to changes in environmental and behavioral factors and their likely interaction with genetic factors. Among the environmental factors, a frequently-cited possible cause of the asthma epidemic is changes in diet, particularly decreased consumption of fresh fruit and vegetables and increased consumption of "Western" processed foods. ${ }^{2}$ Asthma is a heterogeneous disease, however, and categories such as "childhood asthma" and "adult-onset asthma" are increasingly accepted as different phenotypes. ${ }^{3}$ The role of dietary factors might differ across these two asthma phenotypes.

The association between diet and childhood asthma is moderate, at best, with observational studies reporting "protective" associations for vitamins A and E, zinc, and polyunsaturated fatty acids. ${ }^{2}$ Crosssectional data also suggest a beneficial role for childhood intake of fruit and vegetables and for adherence to a Mediterranean diet, but cohort studies and primary prevention trials are lacking. With regard to adult-onset asthma, the role of diet on incident asthma is weak. ${ }^{2}$ For example, four large longitudinal studies found no association between dietary patterns and risk of adult-onset asthma.

Even if dietary intake appears to have a little more promise as a cause of childhood asthma (as compared to adult-onset asthma), the role of diet as a disease modifier remains largely unexplored. In other words, even if alterations in dietary intake may one day be shown to be unhelpful for the primary prevention of asthma, dietary interventions may still be of help with efforts to achieve asthma control.

To date, few studies have looked at the role of diet as a disease modifier. Among children, recent studies have shown that low levels of vitamin D were associated with worse asthma control. ${ }^{2}$ Among adults, a large French study found that frequent asthma attacks were more common among those with a "Western" dietary pattern and were less common among those with a "nuts and wine" pattern. ${ }^{2}$ Likewise, among Portuguese adults with asthma, a strong association was reported between the Mediterranean diet score and a composite measure of asthma control. ${ }^{4}$

In the current issue of the $P C R J$, Bime and colleagues analysed the cross-sectional association between soy genistein intake with baseline lung function and asthma control among 300 asthmatic adults with poor asthma control. ${ }^{5}$ They also examined the longitudinal association between baseline soy genistein intake and asthma control over a 6month period. The authors report that consumption of a diet with moderate-to-high amounts of soy genistein is associated with better lung function. With regard to asthma control, the association with soy genistein intake was null at baseline but was U-shaped in the longitudinal analysis (i.e., the group with moderate intake had fewer episodes of poor asthma control than those with either low or high intakes). ${ }^{5}$

Genistein, a soy isoflavone with high concentration in soybeans, has several biological activities and may interact with oestrogen receptors to produce oestrogenic or anti-oestrogenic effects. ${ }^{6}$ Health research on soy genistein was a focus for cardiovascular researchers for many years but, according to a comprehensive update by the American Heart Association's nutrition committee, earlier research indicating that soy protein had clinically important favourable effects on cardiovascular health and cancers, as compared with other proteins, was not confirmed. ${ }^{7}$ Accordingly, enthusiasm for soy genistein has waned.

With regard to asthma control, it is unclear if the observed Ushaped association observed by Bime and colleagues 5 is due either to chance or to a threshold effect of soy intake with loss of benefit with higher intake. As noted by the authors, relatively little attention has been paid to soy intake in relation to respiratory or allergic diseases. ${ }^{8-11}$ In a cross-sectional study of young adults in Australia, the consumption of soy beverage was associated with an increased prevalence of current asthma, doctor-diagnosed asthma and bronchial hyperresponsiveness. ${ }^{8}$ In another cross-sectional study among Japanese pregnant women, dietary intakes of total soy product, soy protein, daidzein, and genistein in the fourth quartile (as compared to the first quartile), were independently associated with a reduced prevalence of allergic rhinitis, although no significant dose-response relations were observed. ${ }^{9}$ In a longitudinal study among middle-aged Chinese men and women, total soyfood and soy isoflavone (daidzein, genistein, and glycitein) intakes had modest inverse associations with incident cough plus phlegm. ${ }^{10}$ Among asthmatic adults enrolled in a vaccination trial, the authors noted a cross-sectional association between high consumption of genistein and better lung function. ${ }^{11}$ Overall, three studies out of four were cross-sectional, and the only longitudinal study was on cough plus phlegm (not asthma). The only study focusing on asthma ${ }^{8}$ reported increased risk. Therefore, currently there are few data to support a beneficial effect of soy intake on respiratory outcomes.

With this in mind, we explored possible methodological explanations for Bime et al.'s results. ${ }^{5}$ First, we note that the analyses were not adjusted for socio-economic status. Low socio-economic status has been linked in many studies to worse asthma control ${ }^{12}$ and 
also to lower soy consumption..$^{13}$ Therefore, the lack of adjustment for socio-economic status is an important potential limitation, as the authors themselves recognise. With regard to other potential confounders, it would have been interesting to account for hormonal factors, since oestrogen-related factors are linked to both soy intake and asthma control. ${ }^{6,14}$ Likewise, it is possible that soy intake varies with the intake of other nutrients and foods, and that these other dietary factors may contribute to the observed association.

Although the role of diet on the aetiology of adult-onset asthma appears limited ${ }^{2}$ its role as a disease modifier continues to have promise. Even if we are sceptical about the recommendation to consume the "right" amount of soy to improve asthma control, ${ }^{5}$ we agree with the authors about the value of further research. Randomised controlled trials are needed to truly understand how dietary interventions, including weight loss, ${ }^{15}$ may promote asthma control.

Conflicts of interest The authors declare that they have no conflicts of interest in relation to this article.

Commissioned article; not externally peer-reviewed; accepted 30th October 2012; online 8th November 2012

() 2012 Primary Care Respiratory Society UK. All rights reserved

http://dx.doi.org/10.4104/pcri.2012.00095

Prim Care Respir J 2012; 21(4): 367-368

\section{References}

1. Moorman JE, Zahran H, Truman BI, Molla MT; Centers for Disease Control and Prevention (CDC). Current asthma prevalence - United States, 2006-2008. MMWR Surveill Summ 2011;60 Suppl:84-6.

2. Varraso R. Nutrition and asthma. Curr Allergy Asthma Rep 2012;12:201-10. http://dx.doi.org/10.1007/s11882-012-0253-8

3. Wenzel SE. Asthma phenotypes: the evolution from clinical to molecular approaches. Nat Med 2012;18:716-25. http://dx.doi.org/10.1038/nm.2678

4. Barros R, Moreira A, Fonseca J, et al. Adherence to the Mediterranean diet and fresh fruit intake are associated with improved asthma control. Allergy
2008:63:917-23. http://dx.doi.org/10.1111/j.1398-9995.2008.01665.x

5. Bime C, Wei CY, Holbrook J, Smith U, Wise RA. Association of dietary soy genistein intake with lung function and asthma control: a post-hoc analysis of patients enrolled in a prospective multicentre clinical trial. Prim Care Respir J 2012;21(4):398-404. http://dx.doi.org/10.4104/pcrj.2012.00073

6. Messina M. A brief historical overview of the past two decades of soy and isoflavone research. J Nutr 2010;140:1350S-4S. http://dx.doi.org/10.3945/jn.109.118315

7. Sacks FM, Lichtenstein A, Van Horn L, Harris W, Kris-Etherton P, Winston M. Soy protein, isoflavones, and cardiovascular health. An American Heart Association science advisory for professionals from the nutrition committee. Circulation 2006;113:1034-44. http://dx.doi.org/10.1161/CIRCULATIONAHA.106.171052

8. Woods RK, Walters EH, Raven JM, et al. Food and nutrient intakes and asthma risk in young adults. Am J Clin Nutr 2003;78:414-21.

9. Miyake Y, Sasaki S, Ohya Y, et al. Soy, isoflavones, and prevalence of allergic rhinitis in Japanese women: the Osaka Maternal and Child Health Study. J Allergy Clin Immuno/ 2005;115:1176-83. http://dx.doi.org/10.1016/j.jaci.2005.02.016

10. Butler LM, Koh WP, Lee HP, Yu MC, London SJ. Dietary fiber and reduced cough with phlegm: a cohort study in Singapore. Am J Respir Crit Care Med 2004;170:279-87. http://dx.doi.org/10.1164/rccm.200306-7890C

11. Smith $\amalg$, Holbrook JT, Wise R, et al. American Lung Association Asthma Clinical Research Centers. Dietary intake of soy genistein is associated with lung function in patients with asthma. J Asthma 2004;41:833-43.

http://dx.doi.org/10.1081/JAS-200038447

12. Boudreaux ED, Emond SD, Clark S, Camargo CA Jr. Acute asthma among adults presenting to the emergency department: the role of race/ethnicity and socioeconomic status. Chest 2003;124:803-12.

http://dx.doi.org/10.1378/chest.124.3.803

13. Turrell G, Kavanagh AM. Socio-economic pathways to diet: modelling the association between socio-economic position and food purchasing behaviour. Public Health Nutr 2006;9:375-83. http://dx.doi.org/10.1079/PHN2006850

14. Varraso R, Siroux V, Maccario J, Pin I, Kauffmann F. Epidemiological Study on the Genetics and Environment of Asthma. Asthma severity is associated with body mass index and early menarche in women. Am J Respir Crit Care Med 2005;171:334-9. http://dx.doi.org/10.1164/rccm.200405-6740C

15. Ma J, Strub P, Camargo CA Jr, et al. The Breathe Easier through Weight Loss Lifestyle (BE WELL) Intervention: a randomized controlled trial. BMC Pulm Med 2010;10:16. http://dx.doi.org/10.1186/1471-2466-10-16

\section{Predicting the risk of an asthma attack: the way ahead?}

\section{See linked article by Hyland et al. on pg 405}

\section{*Chris Griffiths', Noreen Clark ${ }^{2}$}

1 Professor of Primary Care, Centre for Primary Care and Public Health, Blizard Institute, Barts and the London School of Medicine and Dentistry, Queen Mary University of London, London, UK

2 Myron E. Wegman Distinguished University Professor, Director, Center for Managing Chronic Disease, University of Michigan, Ann Arbor, Michigan, USA

*Correspondence: Professor Chris Griffiths, Centre for Primary Care and Public Health, Blizard Institute, Barts and the London School of Medicine and Dentistry, Queen Mary University of London, Yvonne Carter Building, 58 Turner St, London, E1 2AB, UK Tel: +44 (0)207 8822509 Fax: +44 (0)207 8822552

E-mail: c.j.griffiths@qmul.ac.uk
Targeting care at those at highest risk of an asthma attack is an attractive concept. Asthma attacks are at best unpleasant, at worst catastrophic and even fatal. Asthma attacks drive health care costs (largely via hospitalisation) and costs to society (via loss of work), ${ }^{1}$ and reducing hospitalisation is the key to reducing the overall costs of asthma care. ${ }^{2}$ The concept of good asthma control fundamentally includes the notion of an individual's likelihood of experiencing an attack. ${ }^{3}$

Risk prediction is growing in importance - both to the individual and at the public health level. Risk scores already exist to predict, for example, the risk of future cardiovascular events, ${ }^{4}$ development of diabetes, ${ }^{5}$ and lung cancer. ${ }^{6}$ UK general practices now routinely use risk-stratification tools to identify - and then target with preventive care - patients at highest risk of hospitalisation.

In this issue of the PCRJ, Hyland and colleagues ${ }^{7}$ report an observational study testing the intriguing hypothesis that a person's risk of a future asthma exacerbation is related to their past attendance 